Sarah Woyciechowski

\title{
Haftungsgrenzen im französischen Deliktsrecht
}

Zur Reichweite der deliktischen Generalklausel in Art. 1382f. Code civil

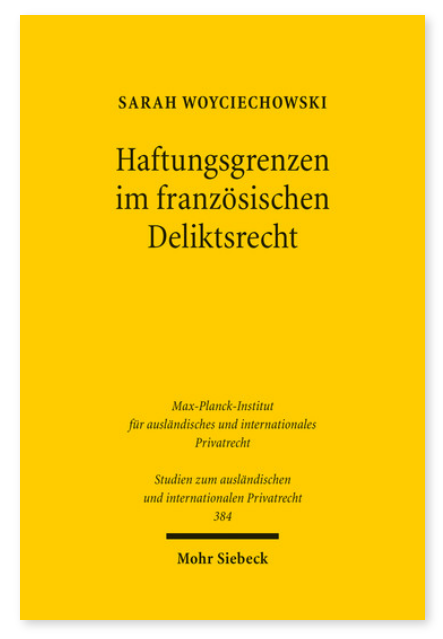

2017. XXII, 382 Seiten. StudIPR 384

ISBN 978-3-16-155268-7

DOI 10.1628/978-3-16-155268-7

eBook PDF 79,00€

ISBN 978-3-16-155267-0

fadengeheftete Broschur 79,00€
Die Frage der adäquaten Formulierung des Schutzbereichs gehört zu den ungeklärten Grundproblemen des europäischen Haftungsrechts. Dem deutschen Modell der »drei kleinen Generalklauseln« steht die unbeschränkte deliktische Generalklausel in Art. 1382 Code civil gegenüber. Sarah Woyciechowski untersucht, woher dieser Gegensatz stammt und inwieweit die unbeschränkte Formulierung des Schutzbereichs der Haftung das französische Recht von Anfang an geprägt hat. Die Autorin zeigt, wie sich die Reichweite der deliktischen Generalklausel im französischen Recht vom ersten Aufkommen einer solchen Generalklausel im Naturrecht über das ancien droit und den Code civil bis in die Gegenwart entwickelt hat. Dies erfordert zeitweise einen differenzierenden Blick auf Lehre und Rechtsprechung, die für die jeweilige Bestimmung des Schutzbereichs mitunter unterschiedliche »Techniken« herangezogen haben.

Sarah Woyciechowski Geboren 1988; Studium der Rechtswissenschaften in Münster und Montréal (LL.M.); Wissenschaftliche Mitarbeiterin am Institut für Rechtsgeschichte in Münster; Research Assistant am Institute of Comparative Law in Montréal (McGill University); 2016 Promotion; derzeit Rechtsreferendarin am Kammergericht Berlin.

Jetzt bestellen:

https://mohrsiebeck.com/buch/haftungsgrenzen-im-franzoesischen-deliktsrecht-9783161552687?no_cache=1 order@mohrsiebeck.com

Telefon: +49 (0)7071-923-17

Telefax: +49 (0)7071-51104 